\title{
НЕПРЕРЫВНОЕ ОБРАЗОВАНИЕ: ПОКАЗАНИЯ К ДИСТАНЦИОННОМУ ИЗУЧЕНИЮ БИОЛОГИЧЕСКИХ НАУК В НАЧАЛЬНОМ И СРЕДНЕМ ОБРАЗОВАНИИ
}

\section{ОРИГИНАЛЬНАЯ СТАТЬЯ}

DENDASCK, Carla Viana1, OLIVEIRA, Euzébio de ${ }^{2}$, FECURY, Amanda Alves ${ }^{3}$, DIAS, Claudio Alberto Gellis de Mattos ${ }^{4}$

DENDASCK, Carla Viana. Et al. Непрерывное образование: показания к дистанционному изучению биологических наук в начальном и среднем образовании. Revista Científica Multidisciplinar Núcleo do Conhecimento. Год 06, эд. 08, Vol. 06, с. 171-186. Август 2021 года. ISSN: 2448-0959, Ссылка доступа: https://www.nucleodoconhecimento.com.br/образование-ru/биологических-наук, DOI: 10.32749/nucleodoconhecimento.com.br/ru/96095

\section{СВОДКА}

Хотя дискуссии о возможности онлайн-образования в начальной и старшей школе в Бразилии вступили в волну теоретических дебатов, все еще существует большое сопротивление. Однако пандемический контекст не принес альтернатив, что привело тысячи студентов к социальной изоляции более чем на год. Этот контекст заставил учителей начальных и средних школ

\footnotetext{
${ }^{1}$ Богослов, кандидат медицинских наук в области клинического психоанализа. Он работает в течение 15 лет с научной методологией (метод исследования) в научно-производственном руководстве магистра и докторантуры. Специалист по маркетинговым исследованиям и исследованиям, специализирующийся на здоровье. Аспирант в области коммуникации и семиотики (PUC SP).

2 Биолог, доктор философии в области тропических болезней, профессор и исследователь курса физкультуры, Федеральный университет Pará (UFPA).

${ }^{3}$ Биомедицина, доктор философии в области тропических болезней, профессор и исследователь медицинского курса кампуса Масара́, Федеральный университет Аmaрá (UNIFAP), проректор по исследованиям и аспирантуре (PROPESPG) Федерального университета Amapá (UNIFAP).

${ }^{4}$ Биолог, кандидат теоретических и летных исследований, профессор и исследователь курса химической степени Института базового, технического и технологического образования Amapá (IFAP) и Высшей программы профессионального и технологического образования (PROFEPT IFAP).
}

RC: 96095

Доступно в: https://www.nucleodoconhecimento.com.br/образование- 
адаптироваться к новым технологиям, тем самым продемонстрировав необходимость подготовки к работе в дистанционном обучении. Вопрос руководства этого материала заключался в том, как могут подготовиться учителя наук о жизни и какие основные инструменты они должны знать, чтобы подготовить свои онлайн-классы? Таким образом, общая цель состояла в том, чтобы выполнить указания, которые учителя должны знать для подготовки своих онлайн-классов. Принятая методология была исследовательской путем обзора литературы. Основные признаки заключались в том, что учителям необходимо искать разнообразное содержание при подготовке классов, чтобы принять стратегии мотивации со своими учениками, проявляя осторожность в вопросе языка, звука и света при производстве классов. Наконец, учитель должен будет распознать различные инструменты и ресурсы, такие как: Youtube, Instagram, Фильмы, Игры и другие субсидии, чтобы было приближение между преподаванием биологии и реальностью ученика.

Ключевые слова: подготовка учителей, дистанционное образование, преподавание биологии.

\section{1. ВСТУПЛЕНИЕ}

С конца 2019 года мир столкнулся с вирусом SARS/COVID-19. Его высокая способность к заражению, вовлечение жизненно важных органов, особенно легких, и невежество научного сообщества привели к тому, что международные организации объявили глобальную пандемическую ситуацию, что указывает на немедленный социальный уход. Эта мера непосредственно повлияла на организации, которым пришлось адаптироваться к новым реалиям, используя, как никогда ранее, технологические средства для обеспечения непрерывности своих соответствующих фрункциональных возможностей. Согласно Gonçalves et al. (2020), в Бразилии одним из наиболее пострадавших учреждений стали школы, особенно государственные, потому что, помимо проблем, касающихся

RC: 96095

Доступно в: https://www.nucleodoconhecimento.com.br/образование- 
доступности технологических инструментов, их учителя не были готовы к этой реальности, и многие сопротивлялись идее онлайн-образования, особенно в средней и начальной школе.

Lenzi и Santos (2021) намекнули, что даже с вакцинами и возвращением к очным занятиям важно, чтобы учителя адаптировались к рутине дистанционного обучения, особенно в том, что было пропагандировано учителями как: гибридное обучение, потому что этот контекст уже является реальностью. Вот почему это исследование должно предоставить некоторые ориентировочные субсидии, которые учителя должны учитывать при подготовке своих онлайн-классов, начиная со следующего вопроса руководства: Как могут подготовиться учителя наук о жизни и какие основные инструменты они должны знать для подготовки своих онлайн-классов? Таким образом, общей целью данного исследования будет: выполнить указания, которые учителя должны знать, чтобы подготовить свои онлайн-классы.

Будут рассмотрены конкретные задачи: а) продемонстрировать основные трудности онлайн-образования биологических наук и важность использования технологий; b) Поиск инструментов, которые могут быть включены в онлайнобразование; с) Предоставить технологические показатели и инструкции, которые должны быть рассмотрены учителем биологии. Так, в теоретической основе был использован широкий поиск в Google Academic, использующий в качестве дескрипторов: «Инструменты для онлайн-обучения биологии»; «ДО Преподавание биологии»; «Гибридное преподавание биологических наук»; «Гибридное преподавание биологии». В качестве критериев включения были рассмотрены материалы, которые могли бы способствовать решению проблемы и достижению поставленных здесь целей. Было отобрано двадцать материалов, в том числе научные статьи, книги и учебные пособия. В их распоряжении, в результатах и обсуждениях был проведен стол с указанием

RC: 96095

Доступно в: https://www.nucleodoconhecimento.com.br/образование- 
основных инструментов и общих соображений, которые должны быть приняты при преподавании онлайн-биологии.

\section{2. ВАЖНОСТЬ НЕПРЕРЫВНОГО ОБРАЗОВАНИЯ УЧИТЕЛЕЙ}

История человечества направляется и конституируется с различных социальных, политических, научных и экономических точек зрения, и все эти аспекты зависят от технологических достижений (TREBIEN et al., 2020). Каждое социальное и системное изменение непосредственно влияет на образовательный процесс в школе, и, таким образом, школьное учреждение должно следовать этим достижениям (RODRIGUES; LIMA; VIANA, 2017). Школа должна адаптироваться к новой модели. Учитывая этот сценарий, профессор активно участвует в процессе, который подразумевает постоянные изменения, чтобы он мог решать проблемы, навязанные обществом. Это связано с тем, что мы живем в инфрормационную эпоху и, таким образом, первоначальная подготовка учителей больше не является достаточным требованием, чтобы гарантировать овладение содержанием и педагогическое качество (JUNGES; KETZER; OLIVEIRA, 2018).

Непрерывное образование признает деятельность, разработанную учителями после первого обучения. Это происходит, когда профессионал входит в профессию учителя. Она может быть индивидуальной или коллективной (TREBIEN et al., 2020). Поэтому он становится незаменимым, процесс формирования, который является постоянным и непрерывным, уходящим корнями в эпистемологию практики и повседневной жизни, способным субсидировать инновационную и сознательную образовательную деятельность (JUNGES; KETZER; OLIVEIRA, 2018). В связи с актуальностью непрерывности педагогического образования Закон о руководящих принципах и основах образования (LDB) содержит главу, в которой подчеркивается этот предмет и обеспечивается поддержка этой подготовки: «[...] связь между теориями и

RC: 96095

Доступно в: https://www.nucleodoconhecimento.com.br/образование- 
практикой, в том числе посредством обучения без работы», после одного абзаца подчеркивается «непрерывная подготовка специалистов на их рабочем месте» (TREBIEN et al., 2020, 94).

C учетом расширения и совершенствования политики, направленной на непрерывное образование, главным образом из-за обеспокоенности качеством преподавания, эта тема вызвала новые действия. Затем необходимо присоединиться к хорошо продуманной программе непрерывного образования с хорошо структурированными целями, включающими не только потребности учителя, но и всю систему образования, вовлекая учителей в этот процесс планирования, который должен быть основанным на широком участии, сотрудничестве и должен учитывать их реальные потребности (RODRIGUES; LIMA; VIANA, 2017). Для того, чтобы их знания и практика были оценены, учитель вместе со своими сверстниками должен размышлять и вести диалог, помогая другим преодолевать свои конфликты (FALSARELLA, 2004). Таким образом, непрерывное образование будет способствовать развитию автономии учителя и динамичности его повседневной практики:

[...] Непрерывное образование как намеренное и плановое предложение, направленное на изменение педагога посредством рефлексивного, критического и творческого процесса, делается вывод о том, что оно должно мотивировать учителя быть активным агентом в исследовании собственной педагогической практики, производя знания и вмешиваясь в реальность (FALSARELLA, 2004, стр. 50).

Непрерывное образование учителя подразумевает принятие непрерывной позиции, которая подразумевает размышление, исследование, действие, открытие, организацию, основание, обзор и теоретическое построение. Она включает в себя не только изучение новых педагогических методов или последних педагогических инноваций (FALSARELLA, 2004). В этом смысле процесс перманентного образования должен основываться на реальности каждой школы, и необходимо, чтобы педагогические собрания и другие

RC: 96095

Доступно в: https://www.nucleodoconhecimento.com.br/образование- 
моменты становления, внутри и вне школы, переосмысливали каждый день, чтобы следить за изменениями самого общества (GADOTTI, 2008). Роль учителя в этом весьма изменчивом и динамичном контекстуализации содержания преподаваемого, так что обучение становится значимым, что требует постоянного упражнения критического осмысления.

[...] поэтому пропозиционированное теоретическое знание формулируется как знание практики, в то же время смиряясь и вновь обозначаясь ими. Роль теории состоит в том, чтобы предложить учителям перспективы анализа, чтобы понять историческое, социальное, культурное, организационное и себя как профессионалов, в которых происходит их преподавательская деятельность, вмешиваться в них, трансформируя их (GHEDIN, 2012, стр. 31).

Необходимо, чтобы профрессор присвоил теорию, чтобы он мог отражать и интерпретировать педагогическую практику в соответствии с требованиями общества, что подразумевает изменения в педагогической практике, чтобы можно было укрепить автономию и динамизм учителя (TREBIEN et al, 2020). Педагогическая практика является отправной и наступающей точкой процесса непрерывного образования и, в то же время, это путь, который позволяет преобразовывать действия учителя и, таким образом, ищет теоретическую основу субсидий, которые позволяют усилить практику рефлексивным, диалогическим и интерактивным способом (GHEDIN, 2012). Поэтому учитель должен быть готов к инновациям, чтобы он мог удовлетворять потребности общества в области преподавания, чтобы он мог трансформировать практику и профессиональную практику (RODRIGUES; LIMA; VIANA, 2017).

C того момента, как мы начинаем размышлять о непрерывном образовании и о том, как оно должно адаптироваться к многочисленным достижениям (в том числе технологическим), требуется целенаправленное осознание социального качества образования и школьной педагогической практики (JUNGES; KETZER; OLIVEIRA, 2018). Таким образом, понятно, что образование эпистемологического и социального качества выступает за фундаментальную

RC: 96095

Доступно в: https://www.nucleodoconhecimento.com.br/образование- 
цель: оно защищает необходимость творческой педагогической практики и стратегии, и, таким образом, оно не должно фрормироваться простым повторением существующих практик (GHEDIN, 2012). В этом смысле необходимо разрабатывать и осуществлять политику, направленную на профессиональную подготовку. В настоящее время те, которые сосредоточены на производительности технологий в классе, имеют основополагающее значение. Это реальность, которая требует осторожности с обработкой теории и практики в обучении упражнениям (TREBIEN et al, 2020).

Однако следует обратить внимание на проблему, с которой сталкивается бразильская система образования. В Бразилии исторически преобладающие модели непрерывного образования отдавали предпочтение чисто инструментальной концепции преподавательской работы (FERREIRA; ALBUQUERQUE, LEAL, 2007). В этом смысле учитель вынужден воспроизводить приемы и пассивно выполняет уже готовые предложения. Замечено, что во многих случаях нормы предписывают модель обучения, которая направляет студента к активному, партисипативному и автономному обучению. Однако на практике эти педагогические знания не сформулированы на курсах непрерывного образования (TREBIEN et al., 2020). Однако продолжение обучения способствует улучшению работы учителя и, как следствие, повышению качества преподавания. Таким образом, для усмирения педагогической практики становится необходимым несколько знаний педагогической практики, что подразумевает постоянный поиск и обучение со стороны преподавателя.

\section{3. ДИСТАНЦИЯ ОБУЧЕНИЯ КАК ИНСТРУМЕНТ НЕПРЕРЫВНОГО ОБРАЗОВАНИЯ}

Использование технологий и дистанционного обучения - это реальность, которую необходимо включить учителям, поскольку пандемия вызвала

RC: 96095

Доступно в: https://www.nucleodoconhecimento.com.br/образование- 
своеобразный разрыв отношений, а, следовательно, и в образовании. Подсчитано, что даже при контроле над COVID школа должна адаптироваться к другой реальности, если не полностью онлайн-обучению,то хотя бы к принятию гибридных моделей (LENZI et al., 2021). Что касается трудностей онлайнобучения, Gonçalves et al., (2020) посчитали отношения между школой и семьей фундаментальными, потому что ученик будет следить за развитием ученика в своем доме. Nicola и Paniz (2016) добавляют, что независимо от выбранной технологии, важно, чтобы учитель помнил, что диверсификация образовательных технологических ресурсов будет иметь важное значение для успеха обучения преподаванию.

Кроме того, необходимо искать среду, которая транслирует повседневную реальность и потребности общества, в которое вставляется студент (ARAÚJO et al. 2011).

[..] «классной комнаты», переведенной в виртуальное пространство, где проводятся уроки, недостаточно для обеспечения желаемого результата. Как и в школе, самыми традиционными способами необходимо учитывать всех задействованных агентов. Следует также сказать, что даже если у кого-то есть понятие, более близкое к реальности, и что у него есть идеал участников процесса, этого недостаточно для обеспечения достижения предлагаемых образовательных целей. Другими словами, речь идет не о том, чтобы иметь компоненты школы и собрать их вместе в одном месте. Что требуется с концепцией школы, так это гармоническая интеграция частей, чтобы работа этого механизма представляет собой минимально возможные грани (SOARES FILHO, 2013, стр. 418).

Olivetti и Periotto (2014), опросив 88 учителей, пришли к выводу, что продолжение обучения имеет основополагающее значение для эфффективности использования технологий в преподавании биологии, потому что одна только биология всегда требовала ресурсов, отличных от теоретических, таких как: лаборатории и полевые исследования. Кроме того, учитель должен иметь в виду, что преподавание биологии является инструментом критического и социального конструировать предмет, а, следовательно, необходимо

RC: 96095

Доступно в: https://www.nucleodoconhecimento.com.br/образование- 
использовать все ресурсы, чтобы у ученика была лучшая успеваемость (LEITE et al., 2017), включая принятие осознания того, что студент должен понимать биологию в своей повседневной реальности (DURÉ et al., 2018).

Переосмысление, таким образом, преподавания биологии, Brandim и Nogueira (2018); Machado (2017) провел размышления о применяемых практиках и возможностях технологических инструментов в преподавании биологии и подчеркнул необходимость того, чтобы учитель искал постоянное обучение, чтобы улучшить результат своей профессиональной практики и свою социальную роль как учителя. Помимо контекста преподавания обучения, ориентированного на преподаваемый предмет, современный учитель должен иметь в виду, что он также становится технологическим педагогом, то есть ответственным за обучение студента использованию технологий конструктивистским способом, указывая на наилучшие варианты использования для построения критического мышления и лучшего усвоения содержания, которое может послужить в их формивном процессе; и, следовательно, вмешательство в цифровое поведение (ROCHA, 2013).

Виртуализация образовательных систем предполагает изменение существующих моделей обучения и методов обучения, и, таким образом, ситуация «вынуждает» учителя брать на себя новые роли, тем самым общаясь способами, к которым он не привык (CARRARI; SOUZA, BEHR, 2017). Учитель не только несет ответственность за передачу знаний своим ученикам, потому что в этот момент он должен руководить процессом обучения студента, чтобы он мог развивать свои способности, то есть ему нужно помогать учиться и, таким образом, развивать его автономию (ROSALIN; CRUZ, MATTOS, 2017). Учитель должен сопровождать, мотивировать, вести диалог, быть лидером, посредником, способствуя и опосредовывая позитивное человеческое взаимодействие (GOULÃO, 2012). Ожидается, что он будет модератором в

RC: 96095

Доступно в: https://www.nucleodoconhecimento.com.br/образование- 
межличностных и внутриличностных отношениях $и$ будет постоянно самостоятельно оценивать свою работу, пересматривая практики.

Внедрение технологий в учебную среду является способом стимулирования студентов, направляя их эмоции, привязанности и отношения (DIAS, 2008). Учитель в этом новом технологическом сценарии должен взять на себя фрункции, которые пробуждают создание и использование цифровых ресурсов, что подразумевает пересмотр их стратегий обучения, усиление взаимодействия с помощью технологий. Для этой динамики необходимо понимать специфику каналов, которые обеспечивают синхронную и асинхронную онлайн-связь (SALMON, 2000). Это требует хорошей структуры коммуникации для создания аутентичного виртуального учебного сообщества, чтобы студент был связан и мотивирован. Регулярное общение со студентами должно осуществляться по разным каналам коммуникации, чтобы они признали, что присутствие преподавателя имеет важное значение. «Пустой» виртуальный класс должен быть уволен (GOULÃO, 2012).

Безжизненная классная комната, без социального и когнитивного присутствия, является «безжизненным» пространством (MOREIRA; FERREIRA; ALMEIDA, 2013). Виртуальные асинхронные коммуникационные классы известны как «форумы». Они являются фундаментальными и отвечают сути цифрового сетевого образования, поскольку не требуют слияния учителей и учащихся в пространстве и времени, и, таким образом, существует большая гибкость в этой образовательной модели (MOREIRA; HENRIQUES; BARROS, 2020). Для того, чтобы эти классы соответствовали мощному инструменту коммуникации, крайне важно, чтобы они были хорошо организованы и структурированы, что требует, чтобы сообщество знало свои операционные правила и следовали им, так что виртуальные цифры способствуют значимому обучению (SOUZA; ARAGON, 2018). Рекомендуется, чтобы в этой виртуальной среде были места для каждого действия.

RC: 96095

Доступно в: https://www.nucleodoconhecimento.com.br/образование- 
Пространство для передачи новостей и уведомлений, другое пространство для ответов на сомнения учащихся, еще одно неформальное пространство, позволяющее более непринужденно взаимодействовать между учениками и учителем, и пространства, созданные для каждого типа деятельности, - вот необходимые стратегии для повышения эфффективности цифровых технологий (MOREIRA; HENRIQUES; BARROS, 2020). Цифровые технологии дают ряд преимуществ, однако постоянное обучение, то есть постоянное, имеет решающее значение, поскольку в этой области постоянно происходят инновации и внедрение новых методов, что требует значительных изменений в практике, профрессор (MOREIRA; HENRIQUES; BARROS, 2020). В этом смысле необходимо знать программное обеспечение, понимать, что предназначено для его использования с педагогической точки зрения, и видеть, является ли этот конкретный цифровой ресурс наиболее подходящим (CARRARI; SOUZA; BEHR, 2017).

Это связано с тем, что простое использование цифровых интерфейсов само по себе не гарантирует достижений или инноваций в образовательной практике (SOUZA; ARAGON, 2018). Некоторые социальные веб-интерфейсы недостаточно используются, когда принятые ссылки все еще повторяют те практики, которые были приобретены в Web 1.0. По этим причинам и, кроме того, понимая цифровое сетевоеобразование как процесс, характеризующийся использованием цифровых технологий Социальной паутины, необходимо продвигать активные и конструктивные педагогические и дидактические практики (ROSALIN; CRUZ; MATTOS, 2017). Знания и обучение должны развиваться совместно. Сетевое образование, в силу своей собственной сущности, является процессом, который требует глубокого вовлечения различных субъектов, участвующих в этой артикуляции, особенно определения целей и путей обучения сообщества.

RC: 96095

Доступно в: https://www.nucleodoconhecimento.com.br/образование- 
Этот процесс также оказывает давление на тесные отношения, построенные совместно между коллегами, которые поддерживают процессы инноваций и создания знаний из цифровых путей (MOREIRA; HENRIQUES; BARROS, 2020). Для коллективного конструя этого нового знания все более распространенным и быстрым становится рост и расширение использования открытых образовательных ресурсов (ООР). Они способствовали доступу и свободному использованию контента и технологий (GOULÃO, 2012). Такие ресурсы соответствуют неисчерпаемому источнику цифровых ресурсов, которые могут быть связаны с деятельностью, направленной на представление и обогащение контента. Существуют платформы, которые допускают различные фрормы подхода к знаниям (платформы, которые интегрируют видео, аудио и изображение, такие как YouTube и другие социальные и цифровые сети / медиа) (SOUZA; ARAGON, 2018).

\section{4. ЗНАНИЯ, НЕОБХОДИМЫЕ ДЛЯ ОБУЧЕНИЯ ОНЛАЙН}

Биологические науки не привилегия сталкиваться с проблемами в учебном процессе обучения, или даже в большей области, чем преподавание и способы преподавания. В контексте онлайн-обучения эти проблемы были только более расширены, требуя от учителя недостаточно развитых технологических навыков. Duré et al. (2018) отмечают, что самая большая проблема учителей как в очном обучении, так и в онлайн-обучении заключается в том, чтобы заинтересовать студентов классами, поэтому, когда они всегда ищут подходы, учитывающие их личные и социальные потребности, процесс обучения имеет тенденцию быть более эффективным. Еще одной стратегией, которая должна быть принята учителями в этом процессе, является широкая диверсификация механизмов обучения, таких как видео на YouTube, фрильмы, игры, разыскиваемые (OLIVETTI и PEIOTTO, 2014; NICOLA и PANIZ, 2017; ARAÚJO et al., 2011; LEITE et al., 2017; LEÃO ARAÚJO et al., 2018)

RC: 96095

Доступно в: https://www.nucleodoconhecimento.com.br/образование- 
Таблица 1- Обучение знаниям и показаниям для онлайн-образования

\begin{tabular}{|c|c|}
\hline $\begin{array}{l}\text { Знания, необходимые для онлайн-преподавания } \\
\text { биологии }\end{array}$ & Авторы \\
\hline $\begin{array}{l}\text { Адаптация занятий в соответствии с реальностью } \\
\text { студента, будь то социальная или личная }\end{array}$ & $\begin{array}{l}\text { Araújo et al. 2011; } \\
\text { Leite et al., } 2017 ; \\
\text { Machado, } \\
\text { Leão et al., } 2017 \text {; }\end{array}$ \\
\hline $\begin{array}{l}\text { Поиск видео, игр, приложений, которые могут } \\
\text { привнести динамизм в преподавание биологии }\end{array}$ & $\begin{array}{l}\text { Araújo et al., } 2011 ; \\
\text { Leão et al., } 2018 .\end{array}$ \\
\hline $\begin{array}{l}\text { Ищите методы оценки, которые вовлекают студента, } \\
\text { включая групповую методологию, такую как } \\
\text { создание выставочных видеороликов }\end{array}$ & $\begin{array}{l}\text { Araújo et al., } 2011 ; \\
\text { Leite et al., } 2017 ; \\
\text { Leão et al., } 2018 .\end{array}$ \\
\hline Концептуальная карта & Leão et al., 2018 \\
\hline Использование викторины (Instagram) & Souza et al., 2020 \\
\hline $\begin{array}{l}\text { Исследования в различных онлайн-СМИ по темам, } \\
\text { выставленным. Пользуясь возможностью развития } \\
\text { критического мышления и анализа некоторых } \\
\text { позиций в это время }\end{array}$ & $\begin{array}{l}\text { Machado, 2017; } \\
\text { Brandim и Nogueira, } \\
2018\end{array}$ \\
\hline $\begin{array}{l}\text { Диверсификация ресурсов Youtube, фильмов, игр, } \\
\text { текстов }\end{array}$ & $\begin{array}{l}\text { Olivetti } \text { и Peiotto, } \\
\text { 2014; Nicola } \quad \text { и } \\
\text { Paniz, } 2017 .\end{array}$ \\
\hline даптация языка, освещен & 3. \\
\hline
\end{tabular}

Источник: Автор

Souza et al. (2020) провели опыт преподавания с помощью инструмента «викторина» в Instagram, как своего рода тестирование знаний. Результаты

RC: 96095

Доступно в: https://www.nucleodoconhecimento.com.br/образование- 
показали, что студенты чувствовали себя мотивированными и взволнованными, в том числе развивая движение за конкурентоспособность между собой. Оценивая, как студенты относились к этому инструменту, результат также был положительным, потому что студенты были вовлечены и мотивированы. Наконец, забота учителя при обучении в Интернете, стремление обновить свой язык в контексте студентов и исследовать их технологические ресурсы, такие как свет и звук, безусловно, будет сделана в качестве стратегии успеха обучения за счет лучшей поддержки студентов (SOARES FILHO, 2013).

Национальная общая база учебных программ (BNCC) указывает на необходимость совместных усилий преподавателей, исследователей и национальных организаций в целях развития основных компетенций бразильских учащихся базового образования, в том числе связанных с цифровой средой (FERREIRA et al., 2021). Они должны быть разработаны таким образом, чтобы удовлетворить повседневные потребности. BNCC представляет десять компетенций, направленных на человеческое и интегральное обучение, включая «цифровую культуру». Таким образом, он занимается развитием навыков и умений, связанных с использованием цифровых технологий в классе, и они должны соответствовать различным социальным практикам (MATTAR et al., 2020). Таким образом, непрерывное образование должно помочь учителям понять, использовать и создавать информационно-коммуникационные технологии (CHIOSSI; COSTA, 2018).

Использование цифровых технологий должно осуществляться критически, существенно, рефрлекторно и этично, внедряя повседневные практики в образовательный контекст. Цель состоит в том, чтобы способствовать коммуникации, доступу, распространению информации, производству знаний, решению проблем, осуществлению протагонизма и авторства в процессе взаимодействия с такими технологиями в образовательном контексте (LEITE; SILVA, 2017). В этом смысле, понимая включение цифровых технологий в

RC: 96095

Доступно в: https://www.nucleodoconhecimento.com.br/образование- 
построение учебно-методологического процесса и в решение повседневных проблем, BNCC предлагает, чтобы профессионалы были обучены, чтобы иметь возможность внедрять цифровые технологии в классах (PIFFERO et al., 2020). Учителя разных уровней образования и нескольких предметов должны развивать навыки и навыки, которые позволяют это включать (CHIOSSI; COSTA, 2018).

Таким образом, национальные программы и политика, предполагающая внедрение технологий в образование, должны способствовать осуществлению стратегий, обеспечивающих эфрфективный доступ к цифровым технологиям, однако по-прежнему существуют многочисленные барьеры и проблемы (LEITE; SILVA, 2017). Информационно-коммуникационные технологии должны выходить за рамки технического и инструментального использования цифровых технологий (PIFFERO et al., 2020). Есть два фрактора, которые могут задержать доступ к цифровым технологиям в классе: фризические и структурные условия и неадекватная подготовка (FERREIRA et al., 2021). Что касается структурирования школ и самой подготовки учителей, то можно выделить Национальную программу образовательных технологий (PROINFO), созданную в 1997 году. Это вызвало новые разработки, достигнув Программы инноваций и подключенного образования. Эти инициативы добавляются к другим, разработанным с 1970-х годов.

Цель состоит в том, чтобы обеспечить вычислительную структуру для школ, с тем чтобы можно было содействовать адекватной квалификации учителей, делая возможным использование TDIC в контексте образования (FERREIRA et al., 2021). В целях разработки конкретной политики в области информационных технологий в целях использования экономики страны технологии стали частью самых разнообразных контекстов, однако они еще не внедрены эффрективно, поскольку по-прежнему трудно внедрить цифровую культуру в классе (CHIOSSI; COSTA, 2018). Однако в связи с необходимостью введения дистанционного

RC: 96095

Доступно в: https://www.nucleodoconhecimento.com.br/образование- 
образования некоторые неравенства были ликвидированы из-за пандемии (SARAIVA; TRAVERSINI; LOCKMANN, 2020). Не только некоторые школы могут продвигать моменты цифрровых встреч с разных платформ, доступ по-прежнему является проблемой.

Кроме того, отсутствие мастерства в отношении использования платформ, сетей и цифровых медиа учителем также затрудняет внедрение технологий в учебную среду. Овладение определенными инструментами и технологиями подразумевает знание таких возможностей. С каждым днем появляются и совершенствуются новые технологии, что требует от учителя постоянного поиска совершенствования своих навыков и навыков, связанных с обращением с такими платформами и цифровыми инструментами (MATTAR et al., 2020). Знания, необходимые для учебного упражнения, пронизывая некоторые области. Они классифицируются по некоторым конкретным категориям (TARDIF, 2010). Это знание дисциплинарного порядка; профессиональные знания; учебные знания и знания, связанные с экспериментальной областью (MATTAR et al., 2020).

Технологические навыки, которые будут возложены на учителя в учебном упражнении, связаны с определенными знаниями и навыками, связанными с обращением с цифровыми сетями и средствами массовой информации (FERREIRA et al., 2021). В этом смысле, чтобы сделать обучение осмысленным и привязанным к использованию технологий, некоторые навыки становятся первостепенными, однако, чтобы они были выполнены, необходимо, чтобы учитель знал необходимые знания об их возможностях использования (PIFFERO et al., 2020). Овладение компьютерными навыками, программным обеспечением, инструментами,медиа и различными виртуальными средами (такими как Google Meet и другие платформы) требует определенной грамотности и свободного владения цифровым языком (CHIOSSI; COSTA, 2018). Учебные курсы должны основываться на этом акценте, чтобы

RC: 96095

Доступно в: https://www.nucleodoconhecimento.com.br/образование- 
преподавание в виртуальной среде способствовало эффрективному, динамичному и привлекательному обучению для студентов.

\section{5. ОКОНЧАТЕЛЬНЫЕ СООБРАЖЕНИЯ}

Основываясь на предположении о приведении некоторых показаний к знаниям учителя в отношении онлайн-обучения, это исследование было основано на исследовательской методологии, ищущей аллюзии и указания в рамках других уже проведенных исследований. Таким образом, чтобы прояснить заключительные соображения этого исследования, был дан ответ на вопрос руководства: как учителя наук о жизни могут подготовиться и какие основные инструменты они должны знать, чтобы подготовить свои онлайн-классы? Исследование показало, что учителя средней и начальной школы должны использовать несколько инструментов и стратегий для подготовки своих онлайн-классов. Недостаточно просто проводить выставочные занятия, необходимо привлекать студентов. Взаимодействие с такими технологиями необходимо стимулировать, однако, чтобы обучение было осмысленным, необходимо овладеть и знать определенные техники, платформы, инструменты и т.д.

Некоторые эфрфективные инструменты, отмеченные в литературе: концептуальные карты, видео на YouTube, фрильмы, игры, поиск Google и другие сети, короче говоря, инструменты, которые развиваются в студенте не только в контексте биологии, но и, которые поощряют сознательное и эфффективное использование технологий. Кроме того, некоторая техническая осторожность является фундаментальной, например: адекватность языка классу, учитывая его возрастную группу, свет и звук. Из-за сценария пандемии и, следовательно, отсутствия классных классов и возможностей выйти на места, это исследование принесло некоторые ограничения, которые можно было бы лучше изучить с помощью исследований с учителями и студентами.

RC: 96095

Доступно в: https://www.nucleodoconhecimento.com.br/образование- 
Указано, что дальнейшие исследования могут проводиться в прикладной манере с учащимися и учителями, исследуя стратегии и инструменты, которые оказываются эфффективными для преподавания онлайн-биологии в средней и начальной школе.

\section{ИСПОЛЬЗОВАННАЯ ЛИТЕРАТУРА}

ARAÚJO, Magnólia Fernandes; SOUSA, Rute Alves; SOUSA, Ivanise Cortez de. Instrumentalização para o Ensino da Biologia. 2 ed. EDFRN, 2011.

BRANDIM, Maria Rejane Lima; NOGUEIRA, Johnson Fernandes. Ensino de Ciências e de Biologia: reflexões e práticas- Parnaíba: Edufpi, 2018.

CARRARO, W. B. W. H.; SOUZA, M.; BEHR, A. Ferramentas de educação a distância utilizadas por profissionais de contabilidade visando a educação continuada. Revista EDaPECl, v. 17, n. 2, p. 144-160, 2017.

CHIOSSI, R. R.; COSTA, C. S. Novas formas de aprender e ensinar: a integração das tecnologias de informação e comunicação (TIC) na formação de professores da educação básica. Texto Livre: Linguagem e Tecnologia, v. 11, n. 2, p. 160-176, 2018.

DIAS, P. Da e-moderação à mediação colaborativa nas comunidades de aprendizagem. Educação, Formação e Tecnologias, v. 1, n. 1, p. 4-10, 2008.

DURÉ, Ravi Cajú; et. al; Ensino De Biologia E Contextualização Do Conteúdo: Quais Temas O Aluno De Ensino Médio Relaciona Com O Seu Cotidiano? Experiências em Ensino de Ciências V.13, No.1, 2018.

FALSARELLA, A. M. Formação continuada e prática de sala de aula: os efeitos da formação continuada na atuação do professor. Campinas, São Paulo: Autores Associados, 2004.

RC: 96095

Доступно в: https://www.nucleodoconhecimento.com.br/образование- 
FERREIRA, L. P. S. et al. Autopercepção das competências digitais pelos professores da educação básica sergipana durante o ensino remoto. Scientia Plena Jovem, v. 8, n. 1, 2021.

FERREIRA, T. B.; ALBUQUERQUE, E. B. C.; LEAL, T. F. Formação Continuada de Professores: questões para reflexão. Belo Horizonte: Autêntica, 2007.

GADOTTI, M. Boniteza de um sonho: Ensinar e Aprender com sentido. São Paulo: Editora e Livraria Instituto Paulo Freire, 2008.

GHEDIN, E. Professor Reflexivo: da alienação da técnica à autonomia da crítica. In: PIMENTA, S. G.; GHEDIN, E (Orgs.). Professor reflexivo no Brasil: gênese e crítica de um conceito. $7^{a}$ ed. São Paulo: Cortez, 2012.

GIL, Antonio Carlos Gil. Método de Pesquisa. Ed. Atlas, São Paulo, 2018.

GONÇALVES, Janaína Oliveira. MIRANDA, Maurício Fernando Oliveira de. GONÇALVES JÚNIOR, Edson. Uma reflexão sobre a parceria da família e escola em tempos de COVID-19: Aspectos pedagógicos, econômicos e jurídicos. Revista Científica Multidisciplinar Núcleo do Conhecimento. Ano 05, Ed. 11, Vol. 06, pp. 141 154. Novembro de 2020. ISSN: 2448-0959, Link de acesso: https://www.nucleodoconhecimento.com.br/educacao/economicos-e-juridicos, DOI: 10.32749/nucleodoconhecimento.com.br/educacao/economicos-e-juridicos

GOULÃO, M. F. The use of Forums and collaborative learning: A study case. Procedia - Social and Behavioral Sciences, n. 46, p. 672-677, 2012.

JUNGES, F. C.; KETZER, C. M.; OLIVEIRA, V. M. A. de. Formação continuada de professores: saberes ressignificados e práticas docentes transformadas. Educação \& Formação, v. 3, n. 9, p. 88-101, 2018.

RC: 96095

Доступно в: https://www.nucleodoconhecimento.com.br/образование- 
LEÃO, Marcelo Franco; et al; Estratégias didáticas voltadas ao ensino das Ciências. Ed. Edibrás. Uberlândia, 2018.

LEITE, M. S.; SILVA, S. R. F. da. Redimensionamento da Computação em Processo de Ensino na Educação Básica: O pensamento Computacional, o Universo e a Cultura Digital. In: VI Congresso Brasileiro de Informática na Educação, 2017.

LEITE, Paula Rayanny Mendonça; et al; O ensino da biologia como uma ferramenta social, crítica e educacional. RECH- Revista Ensino de Ciências e Humanidades Cidadania, Diversidade e Bem-estar. ISSN 2594-8806 - 400. Ano 1, Vol 1, Número 1, Jul-Dez, 2017, p. 400-413

LENZI, Juliana Fernandes de Almeida Castro. SANTOS, Marijara Barbosa Bragato. Sociedade Pós-Moderna Frente À Covid-19: Educadores Em Ação. Revista Científica Multidisciplinar Núcleo do Conhecimento. Ano 06, Ed. 03, Vol. 11, pp. 100 111. Março de 2021. ISSN: 2448-0959, Link de acesso: https://www.nucleodoconhecimento.com.br/educacao/educadores-em-acao

MACHADO, Claudia Pinto/ Ensino de ciências [recurso eletrônico]: práticas e exercícios para a sala de aula- Caxias do Sul, RS: Educs, 2017.

MATTAR, J. et al. Competências e funções dos tutores online em educação a distância. Educação em Revista, v. 36, 2020.

MOREIRA, J. A.; FERREIRA, A. G.; ALMEIDA, A. C. Comparing communities of inquiry in higher education students: one for all or one for each? OpenPraxis. Internacional Council for Open and Distance Education, v. 5, n. 2, p. 165-178, 2013.

MOREIRA, J. A.; HENRIQUES, S.; BARROS, D. M. V. Transitando de um ensino remoto emergencial para uma educação digital em rede, em tempos de pandemia. Dialogia, n. 34, p. 351-364, 2020.

RC: 96095

Доступно в: https://www.nucleodoconhecimento.com.br/образование- 
NICOLA, Jéssica Anese; PANIZ, Catiane Mazocco. A importância da utilização de diferentes recursos didáticos no ensino de biologia. Infor, Inov. Form., Rev. NEaDUnesp, São Paulo, v. 2, n. 1, p.355-381, 2016. ISSN 2525-3476.

OLIVETTI, Maria Madalena de Carvalho; PERIOTTO, Fernando. biologia e as novas tecnologias educacionais, um foco para a educação contemporânea. Revista Eletrônica Científica Inovação e Tecnologia Universidade Tecnológica Federal do Paraná Câmpus Medianeira. Vol.1, p. 9- 2014.

PIFFERO, E. de. L. F. et al. Metodologias Ativas e o ensino de Biologia: desafios e possibilidades no novo Ensino Médio. Ensino \& Pesquisa, v. 18, n. 2, p. 48-63, 2020.

ROCHA, Jéssica. A percepção da ciência pelos alunos do curso de pedagogia UAB/UFMG. V Seminário Internacional de Educação a Distância. UFMG, 2013.

RODRIGUES, P. M. L.; LIMA, W. dos. S. R.; VIANA, M. A. P. A importância da formação continuada de professores da educação básica: a arte de ensinar e o fazer cotidiano. Saberes Docentes em Ação, v. 3, n. 1, p. 28-47, 2017.

ROSALIN, B. C. M.; CRUZ, J. A. S.; MATTOS, M. B. G. de. A importância do material didático no ensino a distância. Revista on line de Política e Gestão Educacional, v. 21, n. 1, p. 814-830, 2017.

SALMON, G. E-Moderating. The Key to Teaching and Learning Online. London: Kogan Page, 2000.

SARAIVA, K.; TRAVERSINI, C. S.; LOCKMANN, K. A educação emtempos de COVID-19: ensino remoto e exaustão docente. Práxis educativa, v. 15, p. 1-24, 2020.

RC: 96095

Доступно в: https://www.nucleodoconhecimento.com.br/oбразование- 
SOARES FILHO, Daniel. Conteúdos EAD: Pequenos detalhes que fazem a diferença. V Seminário Internacional de Educação a Distância. UFMG, 2013.

SOUZA, Dominique Guimarães; et. al. Redes sociais e o ensino de biologia: O uso do Quis do Instagram como Recurso Didático. Recite - Revista Carioca de Ciência Tecnologia e Educação · December 2020.

SOUZA, S. S. dos. S. de.; ARAGON, G. T. Estilos de aprendizagem e ensino a distância na perspectiva da inclusão. EaD em Foco, v. 8, n. 1, 2018.

TARDIF, M. Saberes docentes e formação profissional. 17ª ed. Petrópolis, RJ: Vozes, 2010.

TREBIEN, M. M et al. Formação continuada de professores: uma epistemologia da prática. Ambiente: Gestão e Desenvolvimento, v. 13, n. 1, p. 91-102, 2020.

Представлено: Сентябрь 2021 года.

Утвержден: Сентябрь 2021 года.

RC: 96095

Доступно в: https://www.nucleodoconhecimento.com.br/образование- 